\title{
Cutaneous Leukocytoclastic Vasculitis in Jose R. Reyes Memorial Medical Center: A 12 year Retrospective Study
}

\author{
Bajracharya S', Ismael DK², Venida MLA ${ }^{2}$
}

${ }^{1}$ Resident, Department of Dermatology, Jose R. Reyes Memorial Medical Center, ${ }^{2}$ Consultant staff, Department of Dermatology, Jose R. Reyes Memorial Medical Center

\begin{abstract}
Introduction: Leukocytoclastic vasculitis (LCV) is the commonest vasculitis of skin affecting small vessels.

Objectives: To study epidemiology, etiology, clinical and laboratory features and treatment outcomes in LCV patients.

Material and methods: This is a Hospital based retrospective analytical study where cases with histological evidence of LCV were collected from pathology database since January 2000 to December 2011. Records were analyzed for variables, clinical features, etiological factors, laboratory results, and treatment outcome.

Results: Of total 98 cases, 70 (71.43\%) were Female and 28(28.57\%) Male. Mean age was 28.35 years (range 1 to 71 years). Palpable purpura was commonest presentation (74.49\%) involving mostly lower limbs (91.84\%). Commonest symptom was abdominal pain $(27.55 \%)$, followed by arthralgia $(25.51 \%)$ and pruritus $(24.49 \%)$. Majority of cases had unknown etiology (69.07\%). Those with documented etiology included infection (25.51\%) and drugs (5.10\%). Leukocytosis was commonest laboratory abnormality. Forty one percentage of patients had complete remission, 33\% improved, $2 \%$ deteriorated and $24 \%$ were lost to follow up.

Conclusion: Females were more affected. Palpable purpura in lower limb was commonest presentation. Majority were idiopathic LCV. Amoxicillin and UTI were commonest among causes of drugs and infection, respectively. Commonest abnormality was leukocytosis. The majority of the cases improved with therapy.

Key words: Leukocytoclastic vasculitis, Palpable purpura, Henoch-Schönlein purpura, Hypersensitivity vasculitis
\end{abstract}

\section{Introduction}

V asculitis is defined as an inflammation of the blood vessel wall, which may occur in association with a wide spectrum of systemic inflammatory conditions, malignancies, precipitated by infections, drugs or may be idiopathic. ${ }^{1-3}$ Vasculitis has been classified based on vessel size (large, medium and small-sized vessels), severity of disease (cutaneous or systemic), clinical signs and symptoms in conjunction with histopathologic features (American College of Rheumatology criteria), histopathologic features only (Chapel Hill Consensus Conference), and primary (idiopathic) versus secondary disease. ${ }^{2}$

Leukocytoclastic vasculitis (LCV) is a reaction pattern of small dermal vessels, almost exclusively postcapillary venules, characterized by a combination

\footnotetext{
Address for correspondence

Dr. Shirapa Bajracharya

Consultant Dematologist

Capital Hospital Pvt.Ltd, Putalisadak, Kathmandu, Nepal

Ph. No: 9851199958

E-mail: shirapa@gmail.com
}

of vascular damage and an infiltrate composed largely of neutrophils, as well as fragmentation of nuclei (karyorrhexis or leukocytoclasis). The pathophysiology of vascular injury may involve

(a) the deposition of immune complexes,

(b) direct binding of antibodies to antigens in vessel walls, and

(c) activation of leukocytes by antibodies with specificity for leukocyte antigens (ANCAs). ${ }^{4}$

Deposition is facilitated when the vessels are dilated and flow velocity is reduced. This explains the predilection of LCV for the dependent parts of the body (e.g. the lower leg). ${ }^{5}$

If IgA is primarily involved, there is often systemic involvement and the illness is referred to as HenochSchönlein purpura (HSP), which mainly affects children. Renal involvement is one of the main causes of morbidity in HSP. ${ }^{5}$ Hypersensitivity vasculitis (HV) describes patients with small vessel vasculitis resulting from drug exposure. ${ }^{1}$ Erythema elevatum diutinum (EED) is a chronic, recurrent cutaneous vasculitis that usually occurs in connection with 
autoimmune illnesses, infections (e.g.,HIV), or hematological diseases. The reason for the chronicity of the lesions, which often last for 10 to 30 years, has not been explained precisely and its pathogenesis is also unknown. ${ }^{5}$ In urticarial vasculitis, the duration of lesions is longer than 24 hours, there is presence of purpura and post inflammatory pigmentation, and symptoms of burning rather than itching as in urticaria. $^{1}$

LCV most often manifests clinically as dependent palpable purpura distributed symmetrically. They may occur anywhere, but are most commonly found on dependent areas such as the lower legs. ${ }^{2,6} \mathrm{It}$ is associated with the following conditions: idiopathic (45\%-55\%), infection (15\%-20\%), inflammatory disease (15\%-20\%), drug intake (10\%-15\%), and malignancy $(<5 \%){ }^{2}$

The first line of therapy for LCV is to eliminate eliciting infectious agents, drugs or food or treat the underlying diseases. Medications include antihistamines, corticosteroids, colchicines, dapsone and pentoxifylline. ${ }^{4}$

To date, there is no study investigating cutaneous vasculitis at length in our institution. Therefore, a retrospective study was conducted to determine the demographics, incidence, clinical features, possible underlying etiologies, laboratory abnormalities, management and outcomes of histologically diagnosed cases of LCV at the department of Dermatology, Jose R. Reyes Memorial Medical Center (JRRMMC).

\section{Objectives}

\section{General Objective}

This study aims to determine the incidence and clinical profiles of patients diagnosed with LCV in a 12 year retrospective review at the department of Dermatology of JRRMMC from January 2000 to December 2012.

\section{Specific Objectives}

1. To determine the demographic profiles of patients histologically diagnosed with LCV.

2. To determine the incidence, common clinical features, possible underlying etiologies and common laboratory abnormalities of patients with LCV .

3. To determine the management and outcome of these patients.

\section{Material and methods}

All histopathologically diagnosed cases of LCV from January 2000 to December 2012 in department of
Dermatology, JRRMMC were included. All patients with incomplete or missing charts and those without histologic confirmation were excluded.

Records or charts of all patients histologically diagnosed with LCV from January 2000 to December 2012 were retrieved and reviewed. Only the patients with confirmed biopsies were included. As stated in the chart, demographic profile, medical data such as clinical diagnosis, accompanying symptoms, location and distribution of lesions, duration of disease, laboratory results if any, possible etiologies, treatments and outcomes were recorded in the data sheet. Patients were considered as having extracutaneous end organ involvement based on evidence from clinical assessment, biochemistry or radiology. Renal involvement was defined as presence of persistent glomerular hematuria and/or proteinuria. Patients were considered to have renal impairment if their serum creatinine level was more than the upper limit of normal. Clinical course was divided into acute (less than 3 months) and chronic (prolonged course of at least 3 months or at least two recurrent episodes) at the time of consultation. ${ }^{9}$ Overall cumulative incidence was also computed. The statistical analysis was done by calculation of mean and standard deviation.

\section{Results}

One hundred fifty-seven cases of LCV were documented in the pathology database at the JRRMMC department of Dermatology from January 2000 to December 2011. Histopathological diagnosis of LCV was made based on the following characteristics: fibrinoid necrosis of vessels, neutrophilic infiltration of vessel walls, perivascular neutrophils, leukocytoclasis, red blood cell extravasation and fibrin thrombus. ${ }^{4}$ Only 98 charts fit the inclusion criteria. The unavailable charts were not included in this study.

\section{Demographic data}

The mean age of patients histologically diagnosed with LCV was $28.35 \pm 16.79$ years, with ages ranging from 1 to 74 years old. Majority of the patients were at the second decade of life (Table 1). Seventy (71.43\%) of the patients were females and 28 (28.57\%) were males. Females were more affected than males in all age groups (Table 1 ).

\section{Clinical presentation}

Palpable purpura was the most common presenting lesion (73/98, 74.49\%) (Figure 1). The lesions most commonly affected the lower limbs (90/98, 91.84\%), 
with 60 patients (61.22\%) having lesions isolated exclusively to the lower limbs. (Table 2). Sixty-eight patients (69.39\%) had accompanying systemic symptoms, the most common of which was abdominal pain (27.55\%) (Table 3 ).

The average duration of the LCV when patients were first seen was $12.26 \pm 23.28$ weeks, ranging from 2 to 192 weeks. Most cases (75/98, 76.53\%) presented acutely ( $<3$ months) (Figure 2 ).

\section{Incidence}

The cumulative incidence rate in 12 years was $0.024 \%$ (98 new histologically diagnosed cases of LCV / 399,295 new cases seen at the department of Dermatology).

\section{Clinical diagnosis and etiologies}

The majority of patients $(53 / 98,54.08 \%)$ were clinically diagnosed simply as vasculitis (Table 4). Majority of the cases 67/98 (69.07\%) were idiopathic. Infection was the next most common cause $25 / 98$ (25.51\%), and UTI $(15 / 98,15.30 \%)$ was the most frequent infection. Other possible etiologies of LCV in our patient population are presented in Table 5.

\section{Laboratory workups}

Laboratory tests were done by $59 \%$ (58/98) of the total patient population. The most common laboratory abnormality was leukocytosis (21.43\%) (Figure 3 ). In cases with abnormal urinalysis (19/98, 19.39\%), UTI was the most common documented finding (17/98, $17.35 \%)$.

Based on the criteria for systemic involvement ${ }^{2}$ abovementioned in the Methodology section, systemic involvement was detected in eight patients (8.16\%), four each in cases diagnosed with Henoch-Schönlein purpura and hypersensitivity vasculitis. Renal involvement was the most common (4/98, 4.08\%).
One of the patients with deranged renal function also had abnormal creatinine levels, gastrointestinal and neurological manifestations.

\section{Treatment}

Oral prednisone was the most commonly used firstline medication (42/98, 42.86\%), followed by topical steroids and colchicine (Figure 4). Fluoroquinolones were the most commonly used antibiotics (11/98, $11.22 \%)$, followed by amoxicillin-clavulanate (4/98, 4.08\%), macrolides and cephalosporins (2/98, 2.04\%), and penicillin V $(1 / 98,1.02 \%)$. Adjunctive medications included antihistamines (51/98, 52.04\%), vitamin C $(22,22.45 \%)$ and NSAIDs (12/98, 12.24\%).

\section{Outcomes}

Majority of the patients improved with therapy (64\%), and $10 \%$ of the patients resolving spontaneously without any treatment. There were no deaths (Figure 5).

Four $(4.08 \%)$ patients were admitted. The mean hospital duration among admitted in the group is 6.25 \pm 4.57 days, ranging from 3 to 13 days. Of the admitted cases, 3 resolved upon discharge and one patient's condition had deteriorated and had left against medical advice. This patient was diagnosed with acute renal failure probably secondary to intra-renal toxic injury, hepatic encephalopathy stage I, alcoholic liver disease, congestive heart failure and was considered to have hepatorenal syndrome.

Even though treatment with oral steroids produced the highest cure rate, it also had an equivalent high failure rate. Topical steroids had the highest rate of non-improvement (Table 6).

There is no correlation between surface area involvement and outcome. All five cases with a generalized presentation had an acute course and 4 cases subsequently resolved with treatment.

Table 1: Distribution of age and gender in cases histologically diagnosed with LCV

\begin{tabular}{|c|c|c|c|}
\hline Age range in years & Female (n, \%) & Male (n, \%) & Total (n, \%) \\
\hline $0-10$ & $6(6.12 \%)$ & $5(5.10 \%)$ & $11(11.22 \%)$ \\
\hline $11-20$ & $17(17.34 \%)$ & $13(13.27 \%)$ & $30(30.16 \%)$ \\
\hline $21-30$ & $18(18.37 \%)$ & $2(2.04 \%)$ & $20(20.41 \%)$ \\
\hline $31-40$ & $9(9.18 \%)$ & $4(4.8 \%)$ & $13(13.27 \%)$ \\
\hline $41-50$ & $10(10.20 \%)$ & $3(3.06 \%)$ & $13(13.27 \%)$ \\
\hline $51-60$ & $6(6.12 \%)$ & $1(1.02 \%)$ & $2(7.14 \%)$ \\
\hline $61-70$ & $2(2.04 \%)$ & $0(0 \%)$ & $2(2.04 \%)$ \\
\hline $71-80$ & $2(2.04 \%)$ & $0(0 \%)$ & $\mathbf{9 8}(\mathbf{1 0 0 \% )}$ \\
\hline Total & $\mathbf{7 0 ( 7 1 . 4 3 \% )}$ & $\mathbf{2 8 ( 2 8 . 5 7 \% )}$ & \\
\hline
\end{tabular}


Table 2: Distribution of lesions in cases histologically diagnosed with LCV

\begin{tabular}{|l|c|c|}
\hline Distribution & Number & Percent (\%) \\
\hline Generalized & 5 & 5.10 \\
\hline Lower Limbs & 60 & 61.22 \\
\hline Lower Limbs/Gluteal & 2 & 2.04 \\
\hline Lower Limbs/Trunk & 2 & 2.04 \\
\hline Lower Limbs/Upper limbs & 16 & 16.33 \\
\hline Lower Limbs/Upper limbs/Gluteal & 2 & 2.04 \\
\hline Lower Limbs/Upper limbs/Trunk & 7 & 7.14 \\
\hline Lower Limbs/Upper limbs/Trunk/Gluteal & 1 & 1.02 \\
\hline Upper limbs & 3 & 3.06 \\
\hline Total & $\mathbf{9 8}$ & $\mathbf{1 0 0 . 0 0}$ \\
\hline
\end{tabular}

Table 3: Accompanying symptoms seen in cases histologically diagnosed with LCV

\begin{tabular}{|c|c|c|}
\hline Accompanying symptoms & Number & Frequency \\
\hline Abdominal pain & 27 & $27.55 \%$ \\
\hline Arthritis/Arthralgias & 25 & $25.51 \%$ \\
\hline Pruritus & 24 & $24.49 \%$ \\
\hline Cough & 17 & $17.35 \%$ \\
\hline Fever & 11 & $11.22 \%$ \\
\hline Myalgias & 10 & $10.20 \%$ \\
\hline Vomiting & 7 & $7.14 \%$ \\
\hline Hematuria & 6 & $6.12 \%$ \\
\hline Edema & 5 & $5.10 \%$ \\
\hline Weakness & 3 & $3.06 \%$ \\
\hline Diarrhea & 3 & $3.06 \%$ \\
\hline Burning sensation & 2 & $2.04 \%$ \\
\hline Burning micturation & 2 & $2.04 \%$ \\
\hline Weight loss & 0 & \\
\hline
\end{tabular}

Table 4: Clinical diagnoses of cases histologically diagnosed with LCV from January 2000 - December 2012

\begin{tabular}{|c|c|}
\hline Clinical diagnosis & Number (\%) \\
\hline Vasculitis & $53(54.08 \%)$ \\
\hline Henoch-Schonlein purpura & $25(25.51 \%)$ \\
\hline Hypersensitivity Vasculitis & $11(11.22 \%)$ \\
\hline LCV & $6(6.12 \%)$ \\
\hline Urticarial Vasculitis & $2(2.04 \%)$ \\
\hline Erythema elevatum diutinum & $1(1.02 \%)$ \\
\hline Total & $\mathbf{9 8 ( 1 0 0 . 0 0 \% )}$ \\
\hline
\end{tabular}

Table 5: Possible etiologies of cases histologically diagnosed with LCV

\begin{tabular}{|c|c|}
\hline Possible etiologies & Number of patients (\%) \\
\hline Idiopathic & $67(69.07 \%)$ \\
\hline Infection & $25(25.51 \%)$ \\
\hline URTI & $4(4.08 \%)$ \\
\hline UTI & $15(15.30 \%)$ \\
\hline Others (unknown) & $6(6.12 \%)$ \\
\hline Drug-induced & $5(5.10 \%)$ \\
\hline Amoxicillin & $2(2.04 \%)$ \\
\hline Paracetamol & $1(1.02 \%)$ \\
\hline
\end{tabular}


Bajracharya S et al.

\begin{tabular}{|c|c|}
\hline Paracetamol+lbuprofen & $1(1.02 \%)$ \\
\hline Herbal medicine & $1(1.02 \%)$ \\
\hline Drug and infection & $1(1.02 \%)$ \\
\hline Penicillin and URTI & $1(1.02 \%)$ \\
\hline
\end{tabular}

Table 6: Outcomes of histologically diagnosed cases of LCV from January 2000 - December 2012

\begin{tabular}{|c|c|c|c|c|}
\hline \multirow{2}{*}{ Drugs } & $\begin{array}{c}\text { Total patients } \\
\text { (n, \%) }\end{array}$ & Resolved & Outcome (n, \%) \\
\cline { 3 - 5 } & $42(42.86 \%)$ & $15(15.31 \%)$ & $13(13.27 \%)$ & $14(14.29 \%)$ \\
\hline Oral prednisone & $36(36.70 \%)$ & $5(5.15 \%)$ & $15(15.46 \%)$ & $16(16.49 \%)$ \\
\hline Topical steroids & $28(28.57 \%)$ & $12(12.24 \%)$ & $10(10.20 \%)$ & $6(6.12 \%)$ \\
\hline Colchicine & $17(17.35 \%)$ & $4(4.08 \%)$ & $8(8.16 \%)$ & $5(5.10 \%)$ \\
\hline Antibiotics & $2(2.04 \%)$ & $\mathrm{N} / \mathrm{A}$ & $2(2.04 \%)$ & $\mathrm{N} / \mathrm{A}$ \\
\hline Dapsone & $2(2.04 \%)$ & $1(1.02 \%)$ & $1(1.02 \%)$ & $\mathrm{N} / \mathrm{A}$ \\
\hline Pentoxifylline & $1(1.02 \%)$ & $\mathrm{N} / \mathrm{A}$ & $1(1.02 \%)$ & $\mathrm{N} / \mathrm{A}$ \\
\hline Indomethacin & $1(1.02 \%)$ & $\mathrm{N} / \mathrm{A}$ & $1(1.02 \%)$ & $\mathrm{N} / \mathrm{A}$ \\
\hline Azathioprine & & &
\end{tabular}

*N/A: Not applicable

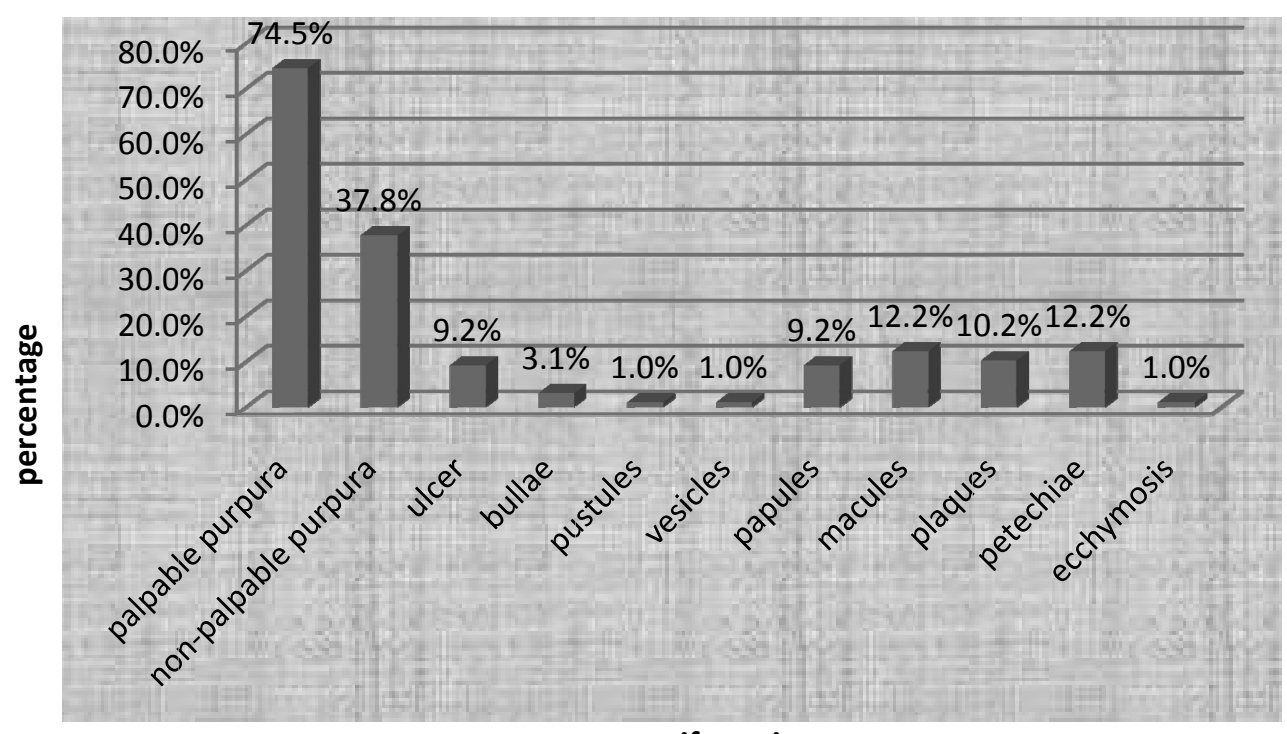

manifestations

Figure 1: Clinical presentations of cases histologically diagnosed with LCV

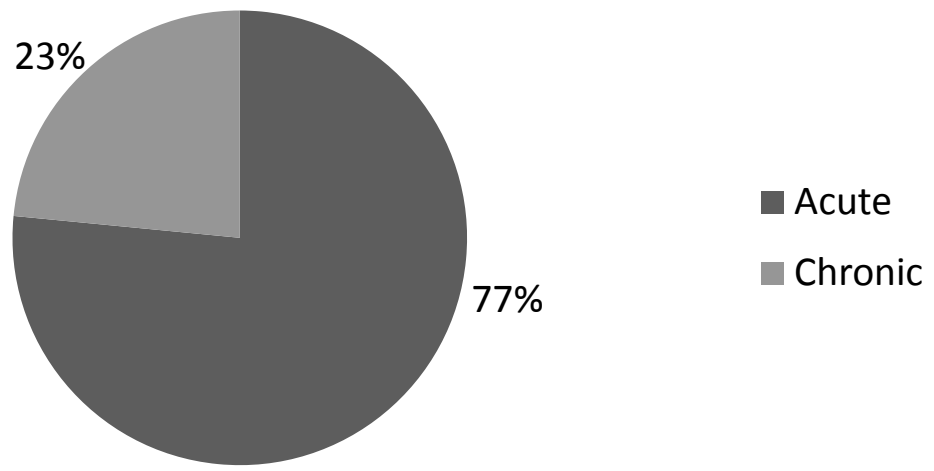

Figure 2: Chronicity of disease in cases histologically diagnosed with LCV 


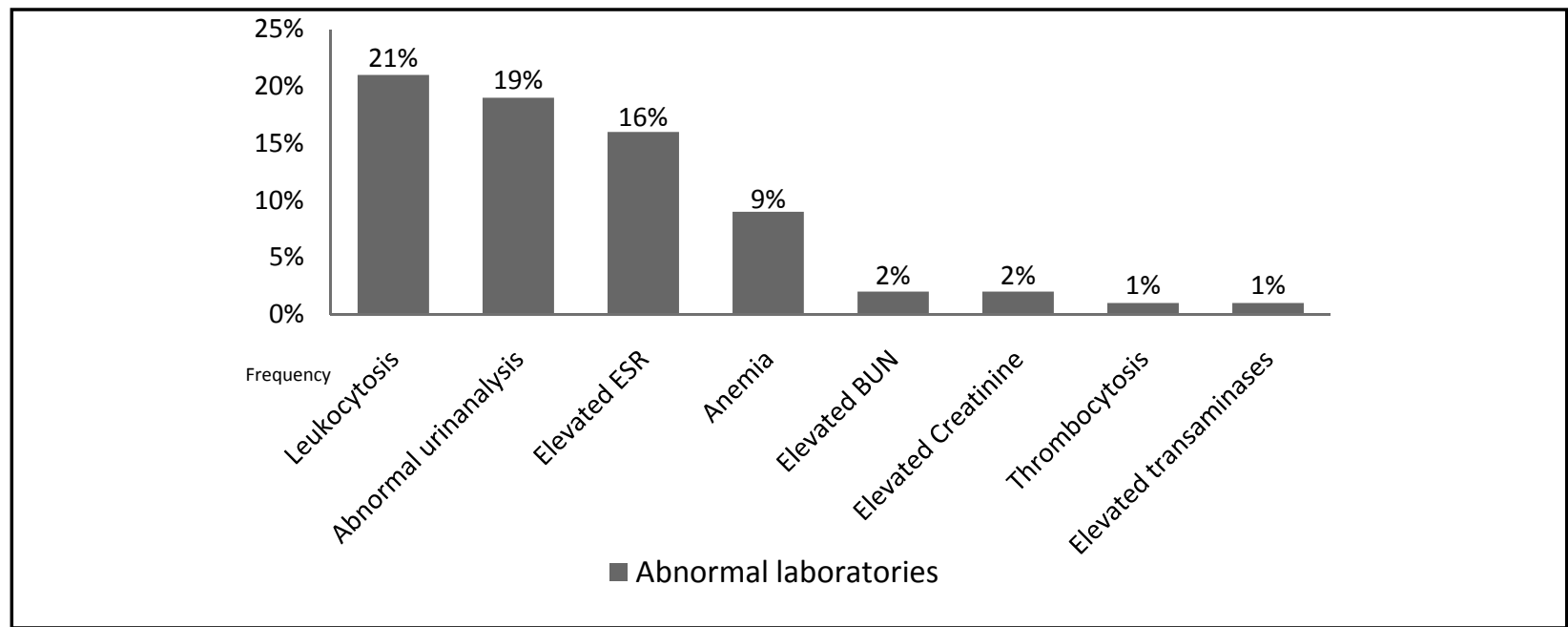

Figure 3: Abnormal laboratories in histologically diagnosed cases of LCV

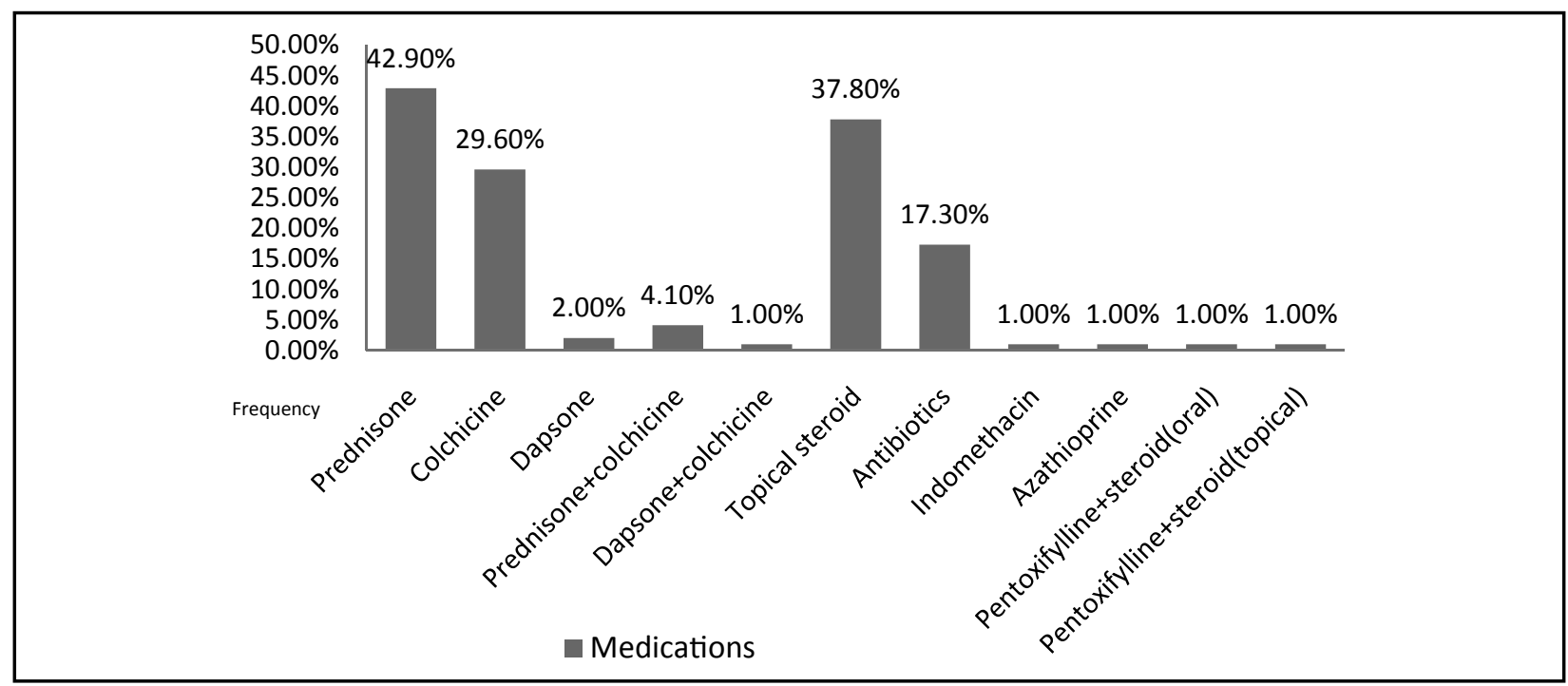

Figure 4: Medications given to histologically diagnosed cases of LCV

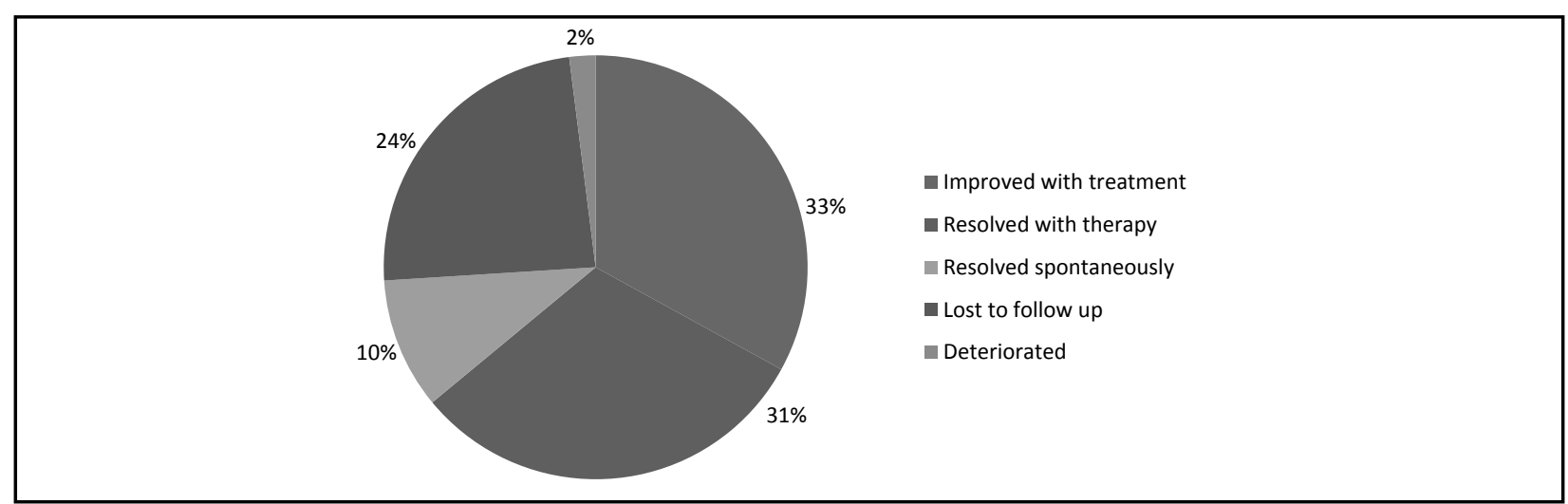

Figure 5: Outcomes of histologically diagnosed cases of LCV from January 2000 - December 2012

\section{Discussion}

The results of our study have shown that patients histologically diagnosed with LCV at the JRRMMC department of Dermatology are most commonly at the $2^{\text {nd }}$ decade of life. This is contrary to other published studies in Asia such as Malaysia ${ }^{7}$ and Singapore $^{8}$ (mean age 36 years old) and in Australia ${ }^{9}$ (mean age 56 years old). There are conflicting studies 
regarding sex distribution, with some reporting male ${ }^{9}$ (Australia), female ${ }^{8}$ (Singapore) or equal distribution ${ }^{7}$ (Malaysia). Our data is in accordance with the data of Singapore ${ }^{8}$. The clinical presentations and site of predilection of our patients are similar to other published reviews. ${ }^{7-9,11}$ As is expected, all patients diagnosed with hypersensitivity vasculitis (HV) (all 11 cases) and majority of HSP patients (23 out of 25 cases) were acute, while cases of urticarial vasculitis ( 2 cases) and EED (1 case) had a chronic presentation.

The majority of the cases in our study have an unknown etiology. Common etiologies were infections and drugs. This is also in accordance to studies done in Singapore ${ }^{8}$ and Australia. ${ }^{9}$ However, unlike in these countries where the most common infection is an URTI, our most common infection is UTI. Amoxicillin and analgesics were the most commonly associated drugs, similar to a retrospective study in Spain. ${ }^{11}$

Complete blood count and urinalysis were the most commonly done laboratory work-ups by the patients, despite the more complete panel that the dermatologists request (liver and renal profile, chest radiograph, ESR, CRP). However, these workups seem to be enough to diagnose concomitant infections and may even reveal renal impairment in some of the patients. Anti-nuclear factor, ANCA, cryoglobulins were not done at our institution since our patients cannot afford such investigations. These workups are reportedly unhelpful in the clinical diagnosis. ${ }^{10}$

There were neither organ malignancies nor association of connective tissue diseases found in any of the cases reviewed in this study. Other countries report the association of these conditions with LCV but this may be due to more specialized centers in their institutions.

\section{Conclusion}

Our retrospective study revealed that in JRRMMC, LCV commonly affects young adults (second decade of life). A female predominance was noted. Presenting symptom and site of predilection are in accordance with previous studies. The most common laboratory abnormality was leukocytosis, but majority had idiopathic LCV. Infections and drugs were common offending agents, usually caused by UTI and amoxicillin, respectively. Most of the patients were managed with steroids and colchicine. The majority of the cases improved with therapy, and some patients resolved spontaneously.

\section{References}

1. Fiorentino DF. Cutaneous vasculitis. J Am Acad Dermatol 2003; 48: 311-40. http://dx.doi. org/10.1067/mjd.2003.212

2. Russell JP, Gibson LE. Primary cutaneous small vessel vasculitis: approach to diagnosis and treatment. International Journal of Dermatology 2006; 45: 3-13. http://dx.doi. org/10.1111/j.1365-4632.2005.02898.x

3. Soter SA, Diaz-Perez JL. Cutaneous Necrotizing Vasculitis. Wolf K, Goldsmith LA, Katz SI, Gilchrest BA, Paller AS, Leffell DJ, editors. Fitzpatrick's Dermatology in general medicine, $7^{\text {th }}$ ed. The McGraw Hill; 2008: p1599-606.

4. Barnhill RL, Nousari $\mathrm{CH}, \mathrm{Xu} \mathrm{X}$, Barksdale SK. Vascular disease. Elder DE, Elenitsas $\mathrm{R}$, Johnson $B L$, Murphy GE, Xiaowei $X$, editors. Lever's Histopathology of the Skin. $10^{\text {th }}$ ed. Lippincott Williams \& Wilkins; 2008: p206-34.

5. Sunderkötter C. Leukocytoclastic vasculitis. CME Dermatol 2008; 3: 32-50.

6. Lotti T, Comacchi C, Ghersetich I. Cutaneous Necrotizing Vasculitis. Int J

Dermatol 1996; 35: 457-74. http://dx.doi. org/10.1111/j.1365-4362.1996.tb01656.x

7. Leelavathi M, Aziz SA, Gangaram HB, Hussein SH. Cutaneous Vasculitis: A Review of Etiology and Clinical Manifestations in 85 Patients in Malaysia. Med J Malaysia 2009; 64: 210-2.

8. Chua SH, Lim JT, Ang CB. Cutaneous Vasculitis Seen at a Skin Referral Centre in Singapore. Singapore Med J 1999; 40: 147-50.

9. Tai YJ, Chong AH, Williams RA, Cumming S, Kelly RI. Retrospective analysis of adult patients with cutaneous leukocytoclastic vasculitis. Australasian Journal of Dermatology 2006; 47: 92-6. http://dx.doi.org/10.1111/j.14400960.2006.00239.x

10. Asad S, Smith AG. Cutaneous vasculitis: a retrospective study. J Am Acad Dermatol 2004; 50: 113. http://dx.doi.org/10.1016/j. jaad.2003.10.377

11. Garcia-Porrúa C, Gonzalez-Gay MA, LopezLazaro L. Drug associated cutaneous vasculitis in adults in northwestern Spain. J Rheumatol 1999; 26: 1942-4. 